\title{
The attributes of residence/workplace areas and transit commuting
}

\author{
Bumsoo Lee \\ University of Illinois, Urbana-Champaign ${ }^{\text {a }}$ \\ James E. Moore II \\ University of Southern California ${ }^{c}$
}

\author{
Peter Gordon \\ University of Southern California ${ }^{b}$ \\ Harry W. Richardson \\ University of Southern California ${ }^{d}$
}

\begin{abstract}
Area type matters when we try to explain variations in public transit commuting; workplace (commuting destination) type matters more than residence (origin) type. We found this statistical link over a sample of all census tracts in the four largest California metropolitan areas: Los Angeles, San Francisco, San Diego, and Sacramento. In this research, we used a statistical cluster analysis to identify twenty generic residence neighborhood types and fourteen workplace neighborhood types. The variables used in the analysis included broad indicators of location and density, street design, transit access, and highway access. Once identified, the denser neighborhoods had higher transit commuting, other things equal. Yet what distinguishes this research is that we did not use a simple density measure to differentiate neighborhoods. Rather, density was an important ingredient of our neighborhood-type definition, which surpassed simple density in explanatory power.
\end{abstract}

Keywords: Commuting; Transit; Neighborhoods; Residence; Workplace

\section{Introduction}

Transit's long-term market share in the United States keeps falling, ${ }^{1}$ although there was a possible uptick (a $10-15$ percent increase in the number of riders in some cities) after the 2007-08 spike in gasoline prices. Many planners hold that the long-term decline can be permanently reversed by reshaping urban form and land-use patterns. Several survey papers review some of the recent work that analyzes the travel effects of neighborhood characteristics (Crane 2000; Ewing and Cervero 2001; Handy 2005).

This paper uses the term "neighborhood" very loosely. Our spatial units are Census Tracts and Census Tract clusters. These may not coincide with neighborhoods defined in traditional ways. Traditional definitions of "neighborhood" in-

\footnotetext{
a Assistant professor, Dept. of Urban and Regional Planning, bumsoo@ illinois.edu.

b Professor, School of Policy, Planning and Development

c Professor, Daniel J. Epstein Dept. of Insustrial \& Systems Engineering

d James Irvine Professor of Urban and Regional Planning, School of Policy, Planning and Development

${ }^{1}$ For all trip purposes, Wendell Cox Consultancy reports that in passenger-miles, public transit's share was $18.26 \%$ in $1950,7.11 \%$ in $1960,3.63 \%$ in $1970,2.82 \%$ in $1980,1.9 \%$ in $1990,1.7 \%$ in 2000 and $1.57 \%$ in 2005. Comparing first-quarter mode shares for 2007 and 2008, www.demographia.com reports an increase, from $1.7 \%$ to $1.8 \%$.
}

clude: areas predominantly inhabited by members of a particular ethnic or cultural group; places with similar housing types; proximate neighbors with shared concerns (e.g. NIMBY or "Not In My Back Yard" situations); areas where communitarianism among households prevails; spatial units for a quantitative analysis based upon homogeneous characteristics; and several others. We preferred the term "neighborhood" to blander terms such as "zone" or "area." The use of Census Tracts was dictated by the data requirements; substituting for Census Blocks, which might have been more easily aggregated into a neighborhood, would have meant some lost variables. There are also neighborhood studies based on the Census Public Use Microdata Sample (PUMS) data, where the spatial units are even larger (Murphy 2010).

Most discussion of the links between neighborhood-level urban form and travel behavior has focused on residential neighborhood attributes. One recent exception is a study by Barnes (2005), who found that large and dense commuting destinations have significant impacts on transit use regardless of the commute's origins, and also suggested that it is easier to increase densities in order to promote transit use in commercial areas than in residential areas. However, Barnes distinguished only between downtowns, central cities, and noncentral-city areas in his analysis. A more recent study on 
mode choice and trip chaining patterns in the Central Puget Sound region (Frank et al. 2008) also found that land-use patterns near the workplace affect mode choice for mid-day and journey-to-work travel.

The research reported here uses data from all Census Tracts across California's four most populous metropolitan areas: Los Angeles, San Francisco, San Diego, and Sacramento. We examine the commuting mode choice effects of generic neighborhood type differences defined across these metropolitan areas. Our research is different from previous studies in two ways. First, we attempt to explore the transit commuting impacts of both residential and workplace neighborhood attributes. Second, we define generic residential and workplace neighborhood types based on extensive data analysis, using cluster analysis rather than selecting just a few transit- versus auto-oriented neighborhoods as in previous research (Cervero and Gorham 1995).

Although this paper is restricted to commuting, researchers have recognized for decades the importance of non-work travel (now 83 percent of all trips) and parallel papers on nonwork trips have been published (Gordon et al. 2006; Gordon and Richardson 1989). Hence, this paper is only a subset of a much broader research inquiry. The scope of the research should be expanded to other metropolitan areas outside California and interdependencies between how commuting and non-work travel affect transit use should also be studied in the future. However, commuting is still important in transit studies because it dictates the peak time demand for the public transportation system.

\section{Literature: Neighborhoods and transit commuting}

Boarnet and Crane begin their book on Travel by Design (2001b) with the statement that "Very little is known about how the built environment influences travel, and there is little agreement on how to reliably learn more." (p. 4). Towards the end of their book, and having surveyed most of the literature and ideas on the topic, they write "...we do not know as much as we would like about the travel impacts of one urban design versus another..." (pp. 177-178).

Transit-oriented development (TOD) is seemingly a narrow topic, but "getting people out of their cars" requires lifestyles that include more walking and bicycling, as well as more transit use. Many hope that such lifestyles can be achieved if the right settings are established. Messenger and Ewing $(1996,145)$ evaluated TOD performance and found that "bus mode share by place of residence proved primar- ily dependent on automobile ownership and secondarily on jobs-housing balance and bus service frequency." Many studies have attempted to estimate the travel impacts of individual variables that measure local area characteristics (Boarnet and Crane 2001a; Cervero and Kockelman 1997). Other papers involve tests of whether residents in different types of neighborhoods vary in their travel behavior. Early research tended to focus on case studies (Cervero and Gorham 1995; Handy 1996), typically comparing auto-oriented postwar suburban neighborhoods with more transit-oriented communities. The selection of study areas necessarily depends on prior knowledge of the development of these communities.

More recently, researchers have used rich GIS data to develop various indicators of neighborhood-level spatial characteristics beyond density, including land-use mix, accessibility, and urban design factors (Bagley et al. 2002; Srinivasan 2002). While some studies have found land use variables to have significant travel impacts (Cervero 2002; Frank and Pivo 1994), others have produced more skeptical results (Boarnet and Crane 2001a; Crane and Crepeau 1998).

A key challenge in research on the links between urban form and travel behavior is to examine whether the relationship is causal or mere correlation. Because some authors have found that physical attributes of neighborhoods have little impact on travel behavior after controlling for attitudinal and lifestyle variables (Bagley and Mokhtarian 2002; Kitamura et al. 1997), researchers increasingly recognize that travel choices of individual households are intertwined with their residential location choices (Schwanen and Mokhtarian 2005). If households' preferences for specific travel modes are embedded in their residential location choices, the observed variation in travel behavior associated with different neighborhood characteristics can be attributed to households' selfsorting to some extent (Vance and Hedel 2007). A review of empirical studies on this topic (Cao et al. 2008) suggests that although most studies have found statistically significant effects of neighborhood attributes even after controlling for residential self-selection, the practical significance of the effects has not been fully studied.

There is also a substantial literature on the role of selfselection in determining the level of transit ridership near transit-oriented developments (e.g. Cervero 2007; Dueker and Bianco 1999; Dunphy and Porter 2006). The key idea is that people who choose to live near transit stations (primarily, but not exclusively, rail stations) were already transit users before moving to residences near transit stations, a fact revealed in many surveys. Thus, higher residential densities around transit stations do not solely reflect a reduction in au- 
tomobile dependence and a modal shift. Instead, self-selection results in a "ridership bonus": $40-45$ percent of the residents living within a one half-mile catchment area are typically prior transit users. Although the neighborhood types examined in this paper do not specifically include precisely defined TODs, self-selection nevertheless helps to explain the higher transit commuting rates in neighborhoods with rail access.

The interest of this paper lies in a less-studied aspect of the links between urban form and commuting behavior: which end of the commuting trip has a greater influence on mode choice, residence (origin) or workplace (destination)? While most research has investigated the travel impacts of urban form in residential neighborhoods, there are some exceptions. Chatman (2003) examined the impacts of density and mixed land uses at the workplace, and found that employment density at the workplace is associated with a lower likelihood of auto commuting. A more recent study (Frank et al. 2008) of trip chaining patterns in Seattle used more developed land use and urban form variables and found that land-use patterns near the workplace affect mode choice for mid-day and journey-to-work travel.

Barnes (2005) suggested that the goal of increasing transit commuting can be achieved more easily by focusing on commuting destinations than on origins. He argued that measures to increase densities in commercial areas would attract less political opposition than similar measures in residential areas, and that commute destinations have greater effects on transit ridership than commute origins. However, he distinguished only between downtowns, central cities, and noncentral-city areas, ignoring significant variation among neighborhoods with different characteristics and their transit use impacts.

\section{Research approach}

\subsection{Methodology}

The strategy we adopted to test how neighborhood attributes influence transit commuting involved two major steps. In the first step, we classified all census tracts in the four metropolitan areas into meaningful prototypes of residence and workplace neighborhoods by applying a statistical cluster analysis. In the second step, we tested the significance of neighborhood impacts on transit commuting, controlling for other variables such as household income and commuting time.

In contrast to previous studies that investigated the transit use impacts of individual urban form variables, we examined whether all census tracts in the four metropolitan areas clus- ter into meaningful neighborhood units, and then tested the neighborhood effects on commuting behavior. The findings of Smith and Saito (2001) suggested that meaningful spatial aggregates can be identified using this approach. Further, we studied neighborhood effects not only at place of residence but also at place of work. This approach required two separate cluster analyses with different input variables to obtain the two sets of neighborhood prototypes.

We pooled data from the four regions for the cluster analyses to identify generic neighborhood types in California's four most populous metropolitan areas. Ten variables were used for neighborhood-of-residence clustering. These included measures of the generalized location, street design factors, and transit and highway access of each census tract (Table 1), somewhat similar to the ideas of Krizek (2003a,b). Population density, distance from the core central business district (CBD) of each metropolitan area, and the age of housing stock are standard descriptors of a neighborhood's spatial location. Recent community design principles are premised on the assumption that street design factors (such as street density, intersection density, and cul-de-sac ratios) are associated with pedestrian access, intra-neighborhood connectivity, and ultimately automobile dependence (Krizek 2003a). Access to major transportation infrastructure such as rail transit systems, park-and-ride stations, and highways is also expected to affect commuting behavior. Bus transit access, however, is not included in our analysis on the grounds that it is more likely to be endogenous in explaining transit commuting than exogenous, because bus routes are relatively ubiquitous and flexible.

Table 1 describes the eleven descriptor variables used in the workplace cluster analysis. Employment density and distance from the metropolitan center are general descriptors of a workplace neighborhood. Average job density of neighboring census tracts within a one-mile radius also describes the spatial context affecting local travel conditions. Measures of access to transportation infrastructure such as rail stations, highway interchanges, and airports are also included as important descriptors of workplace neighborhoods.

Industrial composition is another obvious descriptor of workplace areas. We conducted a standard factor analysis to extract four industrial concentration indices from 13 industrial sectors' shares of census tract employment. Four factors were retained based on the Scree test, and the extracted factors were rotated by a variance maximizing (Varimax) principle. Each factor represents a concentration of economic activities with similar characteristics: a) manufacturing and other industrial sectors; b) finance, insurance and real estate (FIRE), and business services; c) retail and services; and d) 
Table 1: Neighborhood attribute variables used in the cluster analyses.

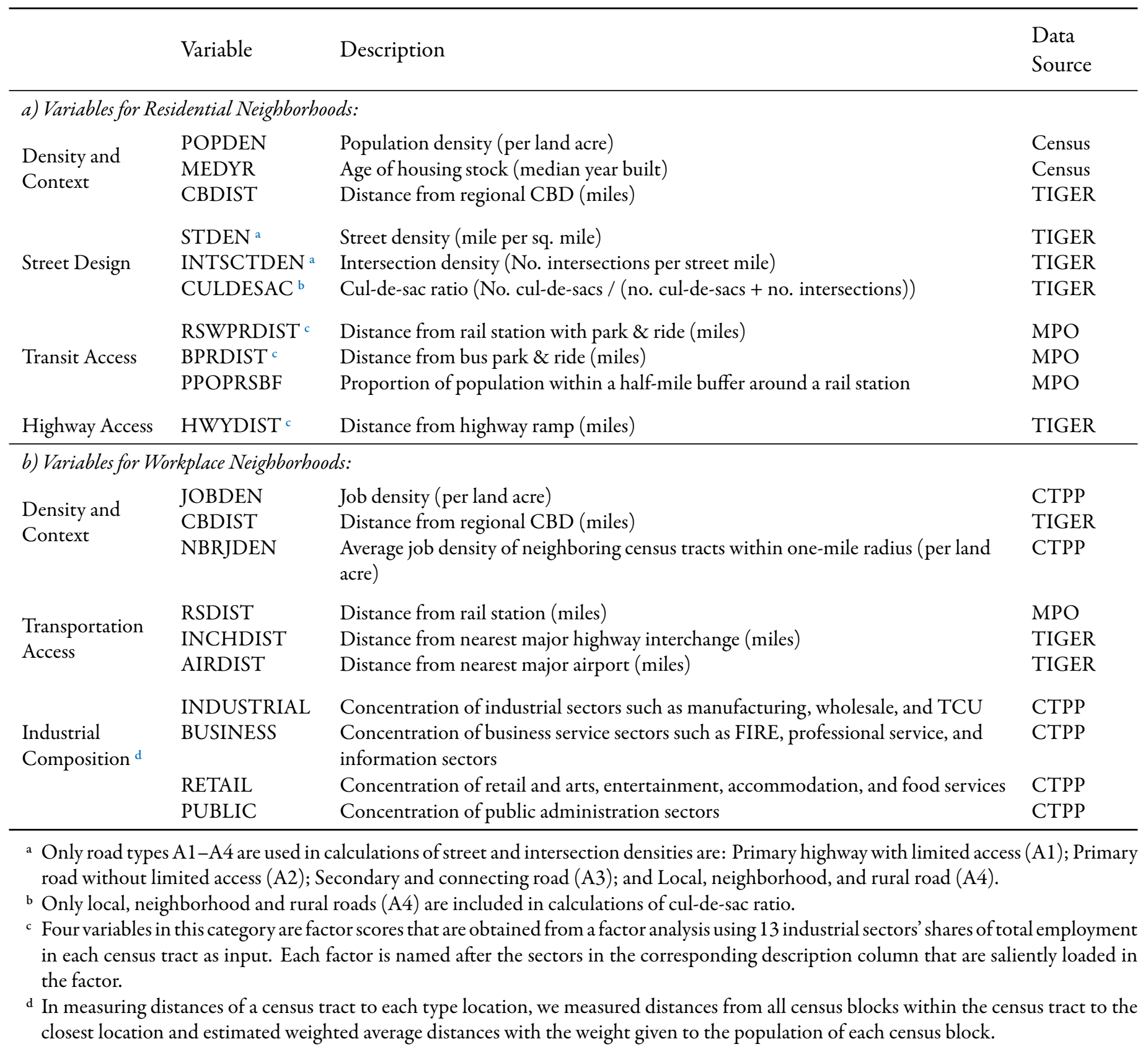


public sectors. These four factor scores, as well as six other workplace attributes, were used in the cluster analysis to identify neighborhood-of-workplace.

We applied a commonly used hierarchical clustering technique, using Euclidean distance as a similarity measure and Ward's minimum-variance method as a hierarchical clustering technique. ${ }^{2}$ We standardized all variables before running the cluster analyses. Twenty clusters of residence tracts and fourteen clusters of workplaces were defined by evaluating the resulting clusters expost. The reasonableness of the size distribution of clusters, their spatial distribution, and the ease of interpreting and evaluating results were taken into account in determining the number of clusters. Some arbitrariness was inevitable given that common statistics such as the Cubic Clustering Criterion, the Pseudo- $F$ statistic, and the Pseudo- $t^{2}$ statistic did not clearly indicate a statistically optimal number of clusters.

In the next step, we tested influences on transit commuting of these neighborhood types, and of traditional explanatory variables such as average commuting time and median household income, using a negative binomial regression model. Because our dependent variable (the number of transit commuters) is a count variable which takes on nonnegative integer values or zero in many instances, the Poisson or negative binomial regression model is an appropriate multivariate technique.

The Poisson regression model assumes that the count variable of interest follows a Poisson distribution:

$$
\operatorname{Pr}\left(Y=y_{i}\right)=\frac{e^{-\lambda_{i}} \lambda_{i}^{y_{i}}}{y_{i} !}, y=0,1, \cdots,
$$

where

$$
\ln \lambda_{i}=\beta^{\prime} x_{i} .
$$

The maximum likelihood estimator of the coefficients is the semi-elasticity of $E(y / x)$ with respect to each covariate (Wooldridge 2002). That is, the percentage change in $E(y / x)$ can be approximated by $100 * \beta_{j} * \Delta x_{j}$, for a small change in $x_{j}$.

However, the Poisson regression model's strong assumption that the conditional variance equals the mean is often violated. Transit commuter counts in our data set were also overdispersed. A common alternative in overdispersion cases is the

\footnotetext{
${ }^{2}$ A study attempting to classify 343 planning districts in Utah's Wasatch Front region based on land-use distribution scenarios found, after applying a series of cluster analysis options, that a combination of the Ward's linkage method and the Squared Euclidean distance measure produced the most reasonable outcome (Smith and Saito 2001).
}

negative binomial regression model, which allows the variance to differ from the mean,

$$
\ln \lambda_{i}=\beta^{\prime} x_{i}+\varepsilon,
$$

where $\exp (\varepsilon)$ follows a gamma distribution with mean 1 and variance $\alpha$.

We used robust error estimation because even a negative binomial model assumes a specific form of the variance, and standard errors would be inconsistent and incorrect when the assumption on the form of the variance distribution is wrong. We also took into account the possible correlation among census tracts within the same metropolitan areas when estimating a regression with pooled data.

\subsection{Data and study areas}

The study areas include all neighborhoods in the four largest metropolitan areas in California: Los Angeles, San Francisco, San Diego, and Sacramento. The analysis uses the 1999 Metropolitan Statistical Area (MSA) definitions from the U.S. Office of Management and Budget (U.S. Census Bureau 1999). The Los Angeles, San Francisco, and Sacramento Consolidated Metropolitan Statistical Areas (CMSAs) include five, ten, and four counties, respectively, while San Diego is a single-county MSA. A neighborhood whether referring to home or workplace locations-is defined as a census tract or a spatial cluster of census tracts.

We relied on journey-to-work data from the 2000 U.S. Census. The 2000 Census Transportation Planning Package (CTPP) (U.S. Census Bureau 2003) was a key data source. This file provides information on commuting and commuters, summarized by place of residence, by place of work, and by commuting flows between origin and destination census tracts. Neighborhood attribute data were drawn from more diverse sources. The 2000 Census Summary File 3 (SF3) (U.S. Census Bureau 2002a) is a rich source of census tract-level housing data that complements the CTPP. When conducting the cluster analysis to identify neighborhoods, we omitted census socio-economic variables because people sort themselves by neighborhood, making these measures endogenous.

We derived most of the variables representing neighborhood level physical attributes via Geographical Information Systems (GIS) technology. We used the 2000 TIGER (Topologically Integrated Geographic Encoding and Referencing system) street networks files (U.S. Census Bureau 2002b) to measure street design factors, often suggested as being closely associated with local and regional accessibility, and hence commuting behavior. GIS map files of rail transit lines were 
also obtained from the metropolitan planning organizations of the four metropolitan areas and were used to measure transit access. All these GIS tasks were executed using ArcView GIS 3.3 software, often using Avenue scripts.

\section{Neighborhood typology}

Twenty residential and fourteen workplace neighborhood prototypes derived from the cluster analysis results are described in Tables 2 and 3, with cluster mean values for the various descriptor variables. For convenience, the two sets of clusters are numbered by population or job densities in descending order. These statistical clusters of census tracts also present strong spatial clusters as shown in Figures 1-4. Census tracts with similar attributes tend to cluster in similar locations. Each neighborhood type's characteristics and locations are briefly described below.

\subsection{Residence neighborhood typology}

The spatial distribution of the twenty residential neighborhood types (Rtypes) approximately fits the following broad categories of general urban spatial models: downtown, inner city, inner suburbs, outer suburbs, and exurban communities. Los Angeles is best known to the authors, and the following interpretation of residence neighborhood types heavily reflects Los Angeles references.

Rtype 1 consists of high density apartments and commercial mixed-use communities adjacent to Los Angeles and San Francisco downtowns. Koreatown in Los Angeles and Chinatown in San Francisco belong to this category. The older apartment buildings are generally two-story structures while the newer ones tend to have three or four stories. These areas have dense street networks and usually have relatively good rail transit and highway access.

Rtypes 2, 3, and 5 are primarily inner city communities, accounting for about 14 percent of total population. Rtypes 2 and 3 are small clusters of high density census tracts in core central cities and in secondary cities such as Long Beach, Glendale, and Pasadena in the Los Angeles CMSA, and Oakland and Berkeley in the San Francisco CMSA. Rtype 2 and 3 communities have similar attributes except that Rtype 3 contains somewhat older communities and has denser and more irregular street patterns. Most of the Rtype 2 communities are found in the Los Angeles metropolitan area. Rtype 5 describes typical small-lot inner city neighborhoods mostly found in Los Angeles and San Francisco, and in some old secondary cities such as Long Beach, Pasadena, Burbank, Santa Ana,
Berkeley, and Oakland, but not in San Jose. It includes the oldest housing stock, high street densities, and the fewest culde-sacs.

Rtypes 4 and 7 are characterized by good rail transit access. In particular, 92 percent of residents in Rtype 4 neighborhoods live within a half-mile of a rail transit station. Core $\mathrm{CBD}$ areas of all four metropolitan areas and downtowns of some secondary cities with good transit access belong to this category. Rtype 7 areas with good transit access but lower density are lined up along rail transit lines in each region. Both Rtypes 4 and 7 also have good highway access because most transit lines are built along major highways.

Rtype 6 areas are typical inner-ring suburbs and account for 13 percent of the regions' population. Rtype 6 areas include relatively older suburbs in the San Fernando and San Gabriel Valleys and the South Bay area. Neighborhoods of this type have average densities with fewer cul-de-sacs than outer-ring suburbs. Rtype 10 is another category of inner-ring suburb, but with older homes, lower densities and many more cul-desac streets. Both types of inner-ring suburbs have good highway access.

Rtype 8, accounting for the largest proportion of metropolitan population of any single type (13.1 percent), has attributes closest to the regional average. Compared to Rtype 6 neighborhoods, Rtype 8 neighborhoods are relatively new and are located farther from regional centers with much higher cul-de-sac ratios. The majority of census tracts in Orange and Santa Clara counties belong to this group. They include many prototypical examples of post-war automobile-oriented suburban development discussed in previous studies (e.g. Cervero and Gorham 1995; Handy 1996; Southworth 1997).

Rtype 13 describes low-density, large-lot residential neighborhoods, often in hilly areas, such as the ones along Mulholland Drive in Los Angeles and the cities of San Rafael and Lafayette near San Francisco. The names of cities dominated by this neighborhood type often end with "Heights."

Rtypes 11 and 15 are typical outer-ring suburbs filling the remaining areas of core urbanized areas. They comprise more than 15 percent of the regions' population. These neighborhoods are relatively new, developed in the 1980s or even later, and are characterized by low densities and high cul-de-sac ratios.

Rtypes 9 and 12 are found in the outer urbanized areas far beyond the core areas. Examples include Riverside, San Bernardino, Ventura, Oxnard, and Temecula in Los Angeles, and Santa Rosa, Napa, Fairfield, Petaluma, and Santa Cruz in San Francisco. Rtype 9 refers to the central areas of these 


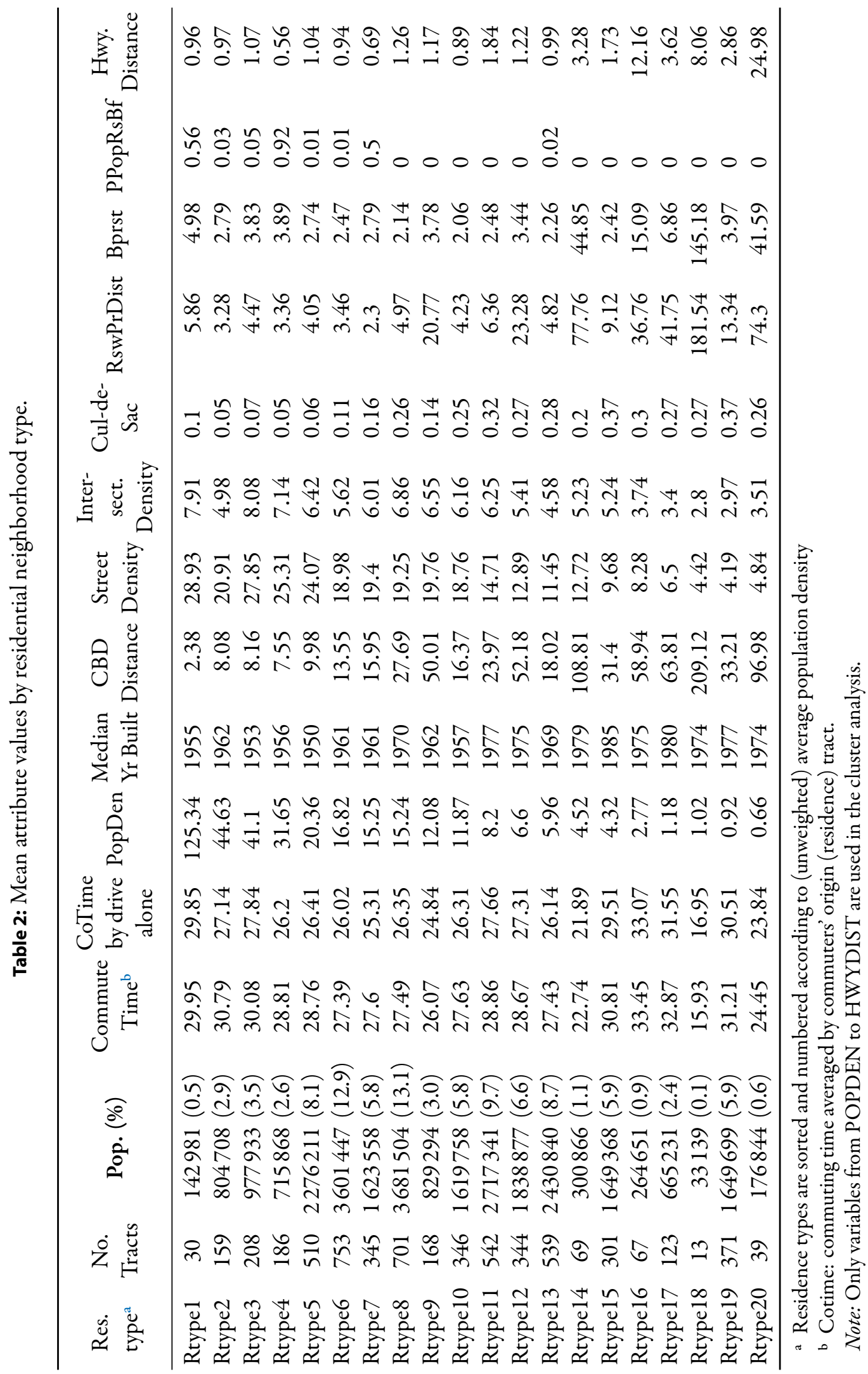




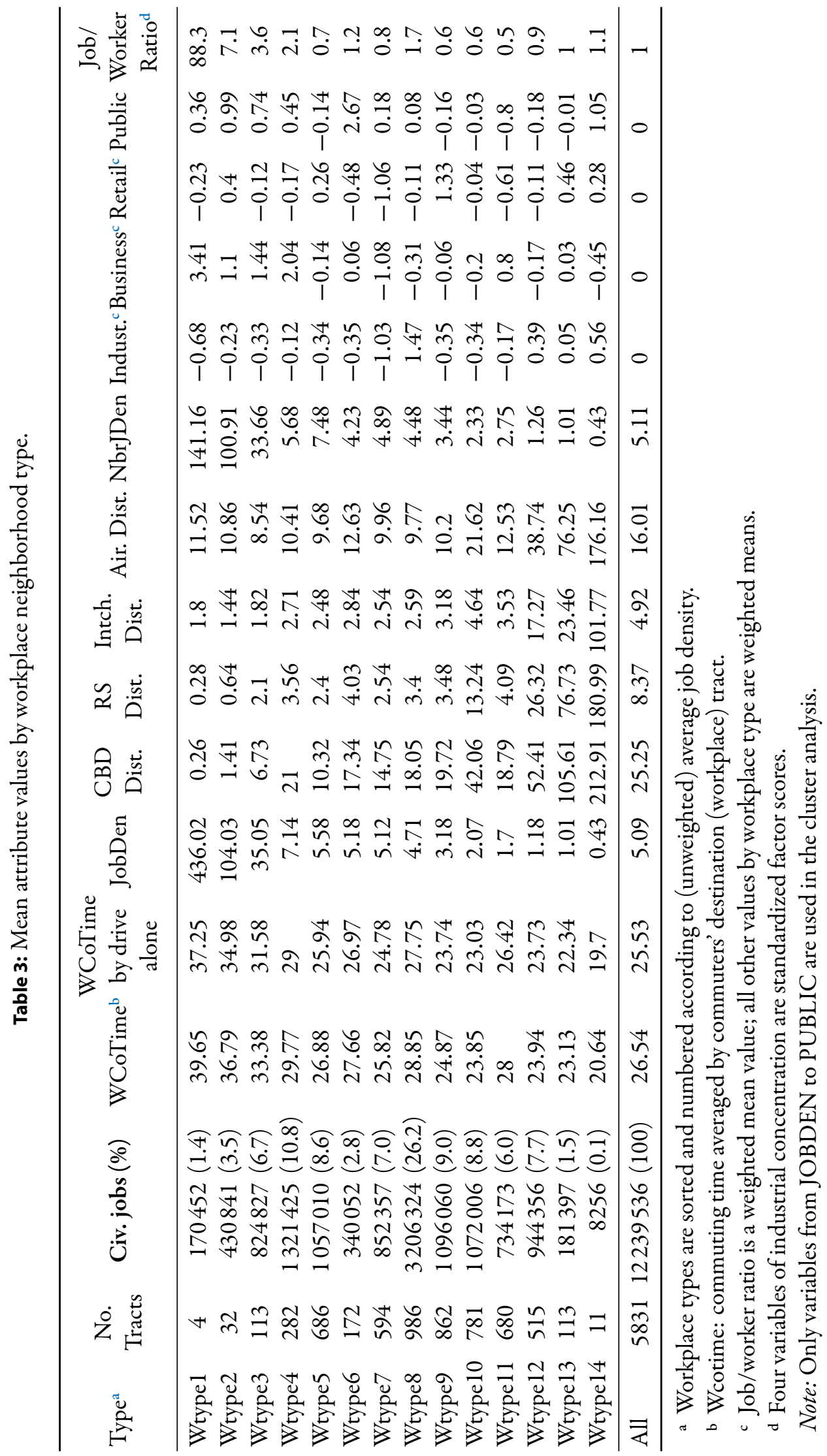




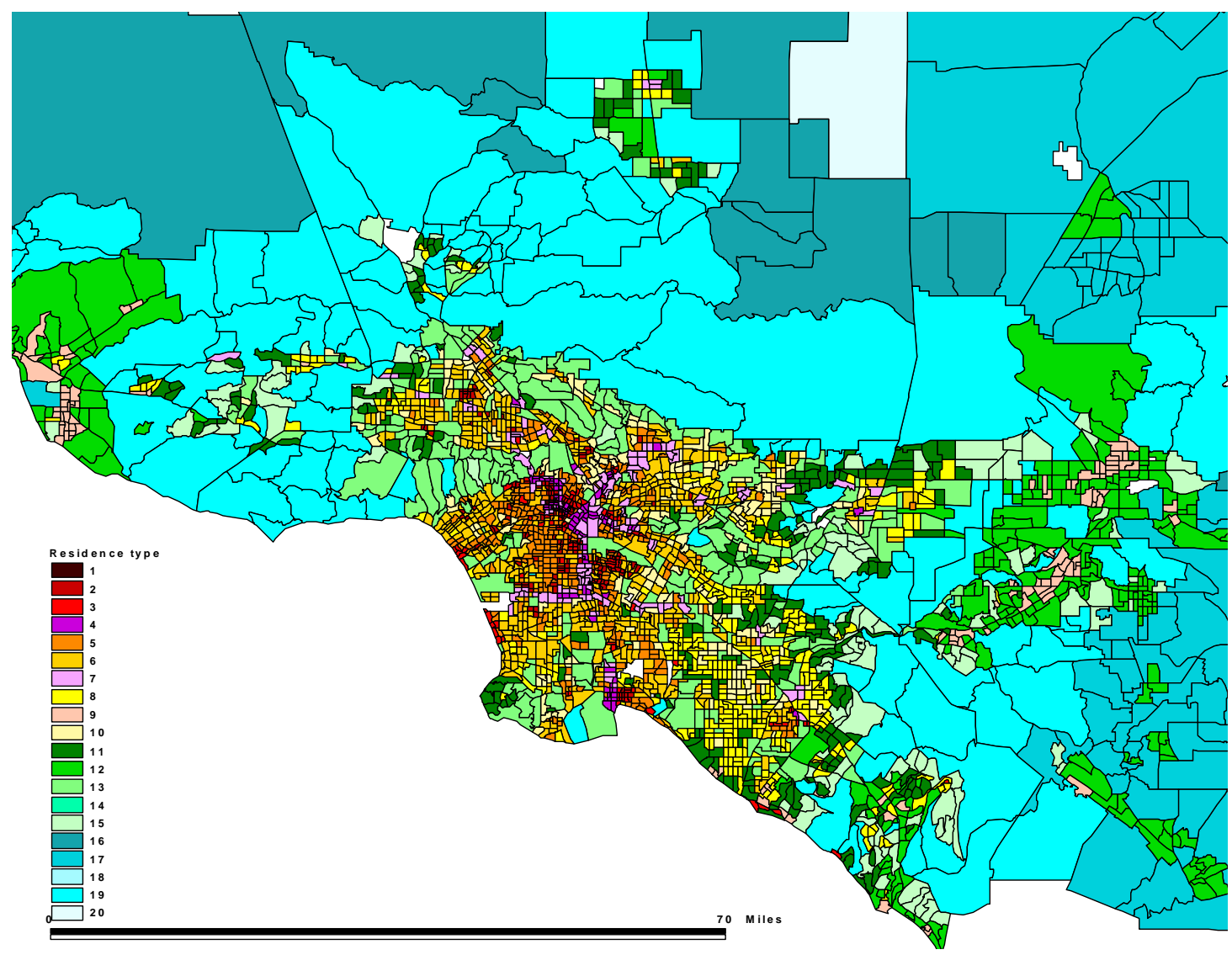

Figure 1: Residential neighborhoods in the Los Angeles metropolitan area.

cities while Rtype 12 describes the rest. Thus, Rtype 9 neighborhoods share attributes of inner-ring suburbs, such as moderate densities and gridded street patterns, despite their peripheral locations.

Rtypes 17 and 19 are exurban communities. Neighborhoods in Rtype 17 are clustered around cities more than 50 miles (and often much farther) from the metropolitan center, and include places like Barstow, Victorville, Hemet, and Temecula in the Los Angeles area, and Santa Rosa in the San Francisco area. Whereas Rtype 17 neighborhoods are clustered in a few locations, Rtype 19 census tracts comprise a complete outer ring surrounding core urbanized areas in the four metropolitan areas. They were primarily developed in the 1970s and 1980s as spillovers from urbanized areas. They are typical auto-oriented neighborhoods with low street densities and very high cul-de-sac ratios. These exurban communities are home to a significant and growing proportion (8.5 percent) of regional populations.
Rtype 14 tracts are found only in the Palm Springs area, which is more than 100 miles away from the Los Angeles CBD.

Neighborhood types 16, 18, and 20 are largely unpopulated mountain and desert areas, accounting for only about 1.5 percent of regional population. Thus, they have little significance for this study.

\subsection{Workplace neighborhood typology}

Generic workplace neighborhood types (Wtypes) in the four California metropolitan areas were also identified from a cluster analysis.

Wtypes 1, 2, and 3 are traditional CBD-type office districts with very high job densities and job/worker ratios. They account for about 11.5 percent of the regions' total employment. Wtype 1 is the financial district in San Francisco with an extremely high job density (436 jobs per acre). Wtype 2 consists of the regional CBDs of the four metropolitan areas and also includes some tightly bounded office districts in 


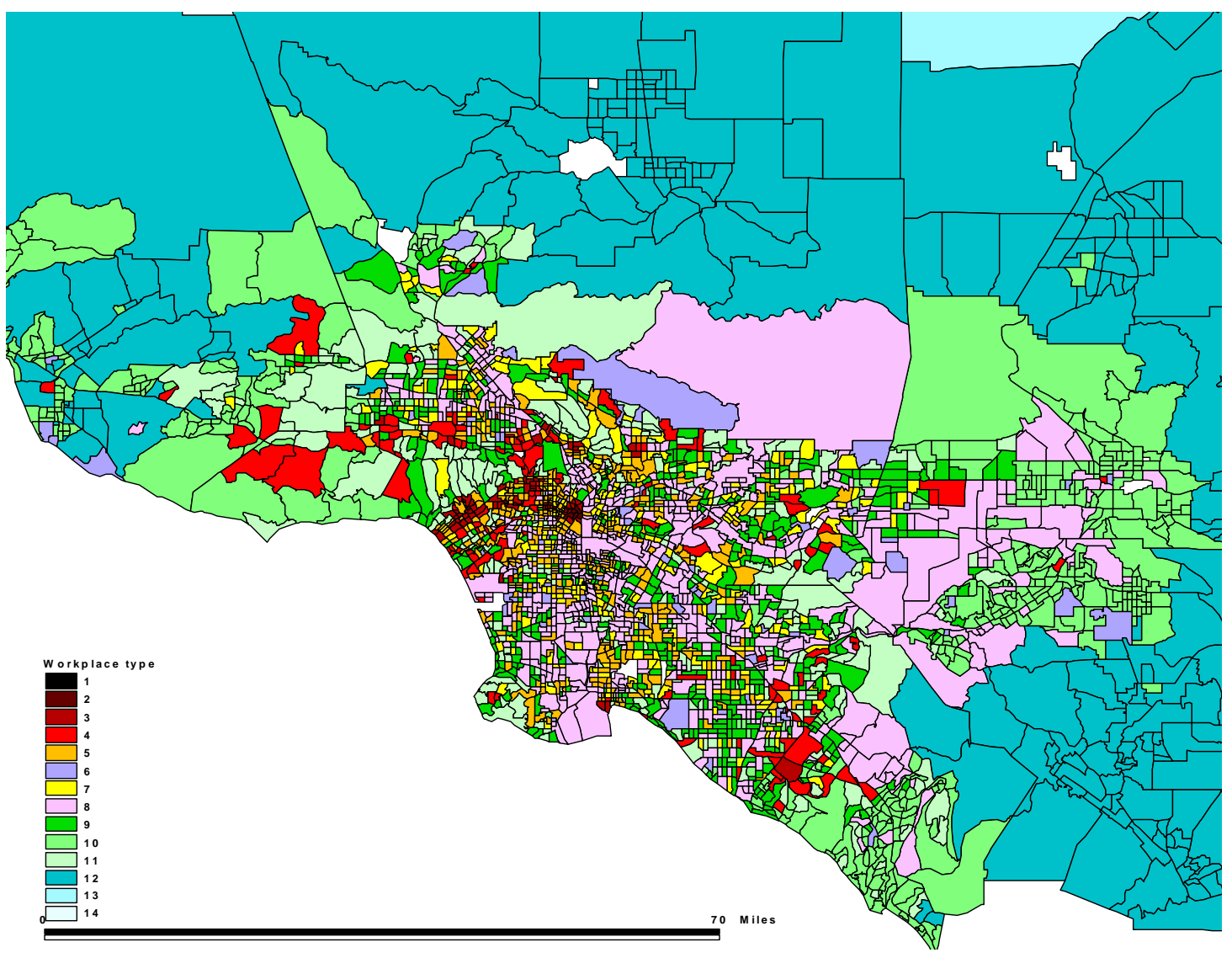

Figure 2: Workplace neighborhoods in the Los Angeles metropolitan area.

West Los Angeles and Oakland. Wtype 3 is made up of census tracts surrounding Wtype 2 districts and secondary CBDs in each region. Wtype 3 includes office and commercial districts along the Wilshire Corridor and downtowns of San Jose, Long Beach, Pasadena, Glendale, Burbank, Santa Monica, and Irvine. Workplaces in these areas are specialized in business services.

Wtype 4 consists of less centralized business services or office centers with much lower job densities, often in suburban locations. Most edge cities listed in Lang (2003), such as North San Jose, Walnut Creek, Pleasanton, and San Ramon in the San Francisco region, and Irvine/Costa Mesa, Sherman Oaks, and Woodland Hills, belong to this group. Wtype 4's job share (10.8 percent) is almost as large as that of downtown employment centers, and is growing.

Wtypes 5, 6, and 7 are medium job density areas with good transportation access. They are primarily located within core urbanized areas, accounting for about 18 percent of the regions' employment. Wtypes 5 and 7 have diversified economic structures except that Wtype 5 is moderately specialized in personal services and Wtype 7 is strongly specialized in educational services (Location Quotient $L Q=2.39$ ). Wtype 6 areas describe the civic centers of small cities with very high public administration employment shares $(\mathrm{LQ}=9.13)$.

Wtype 8 describes industrial centers with a high concentration of jobs in manufacturing, wholesale trade, transportation, warehousing, and utilities. These types of workplaces account for the largest fraction of total employment (26.2 percent) and about 56 percent of regional employment in the three industrial sectors. They tend to cluster along or close to major highways.

Wtypes 9, 10, and 11 consist of workplace areas dominated by residential uses: the number of residents in these areas is about twice the number of jobs. Wtype 9 areas specialize in population-supporting sectors such as retail and entertainment, food, and accommodation services. These workplace areas have moderate residential densities and are primarily found within the urbanized portions of metropolitan areas. The majority of residential areas in Orange County and San Jose belong to this group. Wtype 10 consists of subur- 


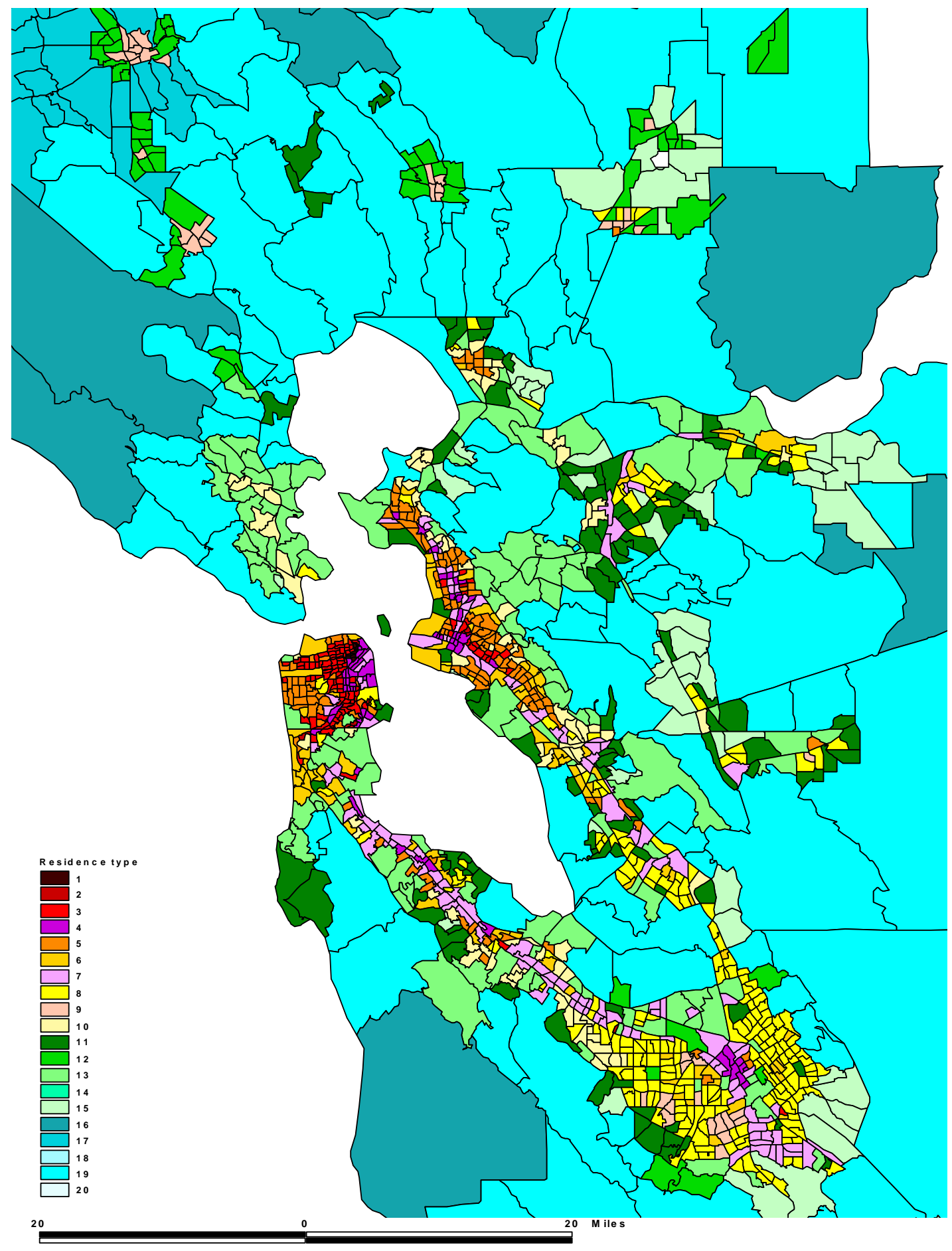

Figure 3: Residential neighborhoods in the San Francisco metropolitan area. 


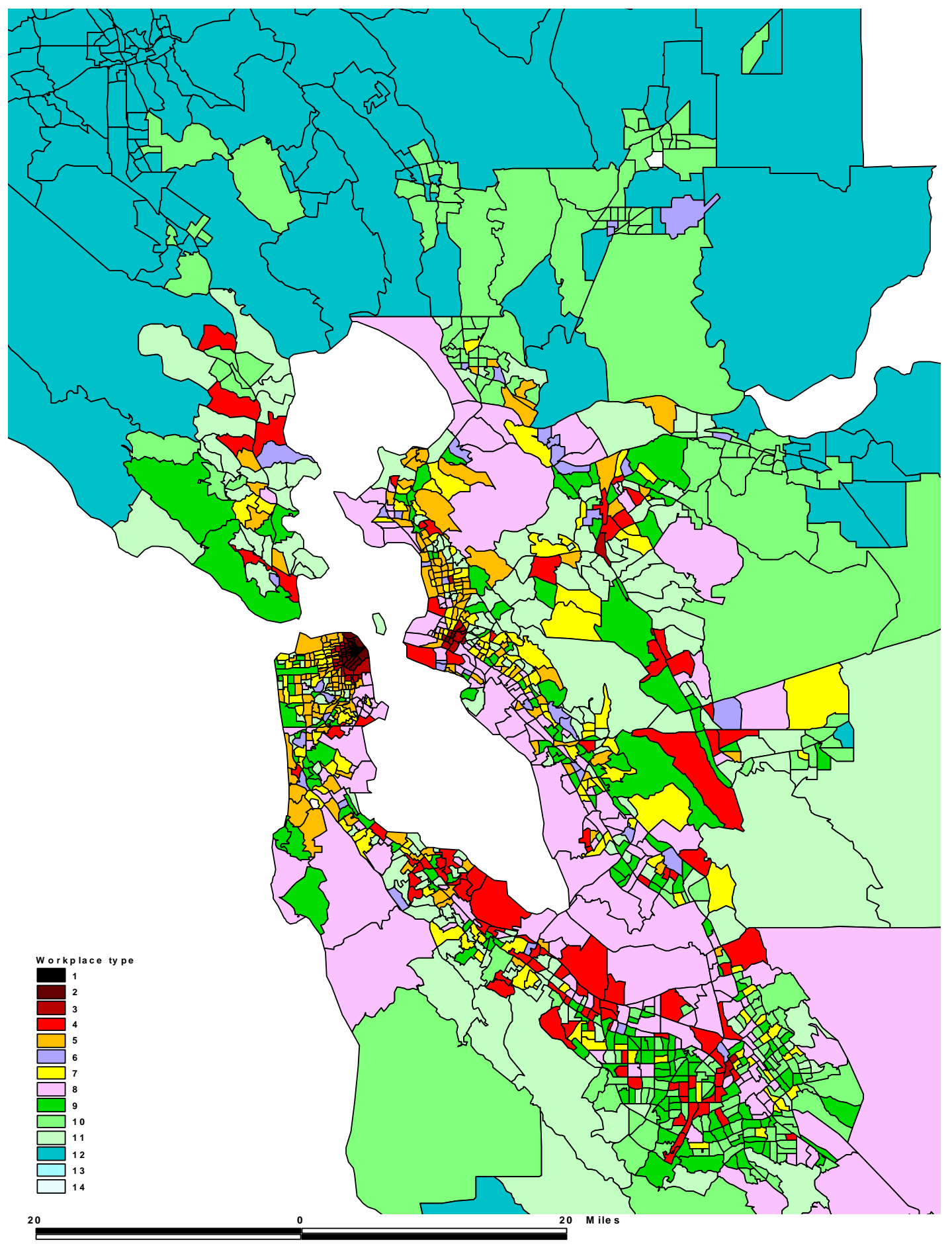

Figure 4: Workplace neighborhoods in the San Francisco metropolitan area. 
ban residential areas with even lower job densities, usually found outside core urbanized areas. Most census tracts in the Riverside-San Bernardino, Oxnard, and Mission Viejo urbanized areas belong to this group. Wtype 11 consists of very-lowdensity areas with moderate to strong specialization in business and other services.

Wtype 12 consists of exurban workplaces with extremely low job densities. Lancaster, Temecula, and Victorville in Los Angeles, and Santa Rosa and Santa Cruz in San Francisco, belong to this group. The shares of agriculture, construction, and manufacturing sectors are above average.

Wtypes 13 and 14 are marginally urbanized areas in fringe locations, and are of little significance for this study.

\section{Neighborhood Attributes and Transit Commuting}

\subsection{Descriptive Analysis}

The percentage rate and share of transit commuters tabulated by residence and workplace types are shown in Tables 4 and 5 . These two tables are aggregated either by commuting origin or destination. For each metropolitan area, the rate column shows the transit users' share of total commuting trips in each neighborhood type-total commuters originating from residential neighborhood types and total commuters destined to workplace neighborhoods. The share columns show each neighborhood type's market share of total transit commuters in each region.

The transit users' share of total commuters was the largest in San Francisco (9.4 percent) and was below five percent in three other metropolitan areas. As expected, the rate of transit use was the highest in high-density inner-city neighborhoods (Rtype1-Rtype3). Combining other inner-city areas (Rtype5), these inner-city neighborhoods accounted for 37 percent of all transit commuters in the four metropolitan regions, while their share of total commuters was only about 14 percent. Residents in rail transit neighborhoods (Rtype 4 and Rtype7) also tended to commute by transit more often than in other areas. Rates of transit use by residents of most neighborhoods in inner-ring and outer-ring suburbs and in exurban communities were below the regions' average, and transit use rates were more or less a function of residential density.

As we expected, transit commuting showed more concentration in terms of commuting destinations than by origins. Regional centers (Wtype1 and Wtype2), where only five percent of regional employment is located, accounted for more than 30 percent of total transit commuters. It is notable that this concentration of transit commuting varies substantially across the four metropolitan areas. San Francisco's regional centers' share of transit commuters was more than 53 percent, while it ranged from about 10 to 23 percent in the other three metropolitan areas.

Each region's secondary centers (Wtype3) also showed higher-than-average transit commuting rates, ranging from about seven to 17 percent. However, transit shares of commuting destined to edge cities (Wtype4) were only one to three percent in all four metropolitan areas-even lower than the metropolitan average. Despite high employment densities, these edge cities are much more accessible by automobiles than by public transportation.

Table 6 shows the percentage of transit commuters for each pair of commuting origin and destination neighborhood types. The figures in Table 6 exclude the cases when the number of commuting flows is too small, so "All" column and row may not be the same as the first columns of Tables 4 and 5 . The 2000 CTPP data indicate that analysis is not statistically meaningful when the number of commuters between given origin and destination census tracts is smaller than 20. Table 6 shows highly concentrated patterns of transit commuting in a few commuting destination neighborhood types. Regardless of commuting origin, transit users' share of total commutes to regional centers was noticeably high.

\subsection{Multivariate statistical analysis}

We conducted a series of negative binomial regression analyses to examine neighborhood effects while controlling for other socioeconomic variables. We compiled a data set for the 5727 census tracts (130 075 pairs of commuting origin and destination tracts) in the four MSAs. Results of negative binomial regressions for the pooled data set and for each MSA are reported in Tables 7-10.

The first column of Table 7 shows that the four control variables were highly significant with the expected positive signs. While we did not require the coefficient of the number of commuters to be one, it was close to a unit in all regressions. As expected, the more commuters below the poverty line and the more minorities for any given pair of origin and destination census tracts, the more transit users in commuting. Consistent with previous studies, transit ridership was higher for longer commutes (as measured by the mean commute time by the drive-alone mode).

Column 2 shows that the control variable effects remain significant when population density in residences (commuting origin) and job density in workplaces (commuting destination) are added to the regressions. Densities at both ends of 
Table 4: Percentage rate and share of transit commuters by residence neighborhood type.

\begin{tabular}{|c|c|c|c|c|c|c|c|c|c|c|c|}
\hline \multicolumn{2}{|c|}{ Residence neighborhoods } & \multicolumn{2}{|c|}{$4 \mathrm{MSAs}$} & \multicolumn{2}{|c|}{ Los Angeles } & \multicolumn{2}{|c|}{ San Francisco } & \multicolumn{2}{|c|}{ San Diego } & \multicolumn{2}{|c|}{ Sacramento } \\
\hline & & Rate & Share & Rate & Share & Rate & Share & Rate & Share & Rate & Share \\
\hline \multirow{3}{*}{$\begin{array}{l}\text { High-density } \\
\text { Inner City }\end{array}$} & Rtype1 & 33.0 & 2.7 & 31.2 & 3.3 & 35.4 & 2.7 & NA & 0 & NA & 0 \\
\hline & Rtype2 & 14.9 & 6.0 & 14.4 & 11.7 & 22.9 & 1.3 & 13.9 & 3.6 & NA & 0 \\
\hline & Rtype3 & 21.6 & 14.2 & 12 & 7.0 & 28.8 & 23.6 & 8.4 & 2 & $\mathrm{NA}$ & 0 \\
\hline Inner City & Rtype5 & 10.3 & 14.1 & 7.6 & 14.7 & 16.9 & 15.4 & 5.2 & 4.3 & 4.5 & 4.5 \\
\hline Rail-transit & Rtype4 & 23.3 & 9.2 & 22.9 & 9.0 & 27.4 & 9.7 & 15.1 & 7.9 & 9.4 & 7.9 \\
\hline Neighborhoods & Rtype7 & 8.5 & 8.6 & 8.2 & 6.9 & 9.7 & 9.7 & 6.0 & 13.1 & 6.2 & 8.3 \\
\hline \multirow{3}{*}{$\begin{array}{l}\text { Inner-ring } \\
\text { Suburbs }\end{array}$} & Rtype6 & 5.5 & 12.0 & 5.1 & 18.1 & 9.2 & 5.2 & 5.4 & 18.9 & 3.9 & 13.0 \\
\hline & Rtype10 & 4.4 & 4.4 & 3.6 & 5.1 & 7.0 & 3.9 & 3.1 & 4.9 & 4.3 & 3.2 \\
\hline & Rtype8 & 3.5 & 8.4 & 3.1 & 8.8 & 4.1 & 7.4 & 4.4 & 12.9 & 2.7 & 9.3 \\
\hline \multirow{5}{*}{$\begin{array}{l}\text { Outer-ring } \\
\text { Suburbs }\end{array}$} & Rtype11 & 2.8 & 5.1 & 1.6 & 3.0 & 6.0 & 5.1 & 2.5 & 9.4 & 2.2 & 27.1 \\
\hline & Rtype15 & 2.1 & 2.4 & 1.2 & 1.3 & 4.3 & 2.6 & 1.4 & 6.3 & 1.8 & 6.1 \\
\hline & Rtype13 & 3.9 & 6.2 & 2.6 & 4.3 & 7.8 & 6.8 & 2.6 & 13.0 & 2.7 & 11.3 \\
\hline & Rtype9 & 2.4 & 1.2 & 1.8 & 1.3 & 3.2 & 1.4 & NA & 0 & NA & 0 \\
\hline & Rtype12 & 2.0 & 2.2 & 1.7 & 3.0 & 2.8 & 1.8 & 1.0 & 0.2 & 0.2 & 0 \\
\hline \multirow{6}{*}{$\begin{array}{l}\text { Exurban } \\
\text { Communities }\end{array}$} & Rtype14 & 1.6 & 0.3 & 1.6 & 0.6 & NA & 0 & NA & 0 & NA & 0 \\
\hline & Rtype17 & 1.0 & 0.4 & 1.0 & 0.5 & 1.3 & 0.3 & NA & 0 & 0.5 & 0.3 \\
\hline & Rtype19 & 2.1 & 2.2 & 1.2 & 1.0 & 3.9 & 3.1 & 1.2 & 3.3 & 1.1 & 5.0 \\
\hline & Rtype16 & 0.7 & 0.1 & 0.7 & 0.1 & 1.0 & 0.1 & 0.5 & 0.2 & 0.1 & 0 \\
\hline & Rtype18 & 0.5 & 0 & 0.5 & 0 & NA & 0 & NA & 0 & NA & 0 \\
\hline & Rtype20 & 1.8 & 0.2 & 0.8 & 0.1 & 1.5 & 0 & 0.2 & 0 & 3.4 & 3.8 \\
\hline \multicolumn{2}{|l|}{ Average/Total } & 5.7 & 100 & 4.6 & 100 & 9.4 & 100 & 3.5 & 100 & 2.7 & 100 \\
\hline
\end{tabular}

Note: Public transit includes five commuting modes: bus or trolley bus; streetcar or trolley car; subway or elevated rail; surface railroad; and ferryboat.

the commuting trip had similar effects on transit commuting ridership as measured by the elasticity (approximately 0.36 ) in the pooled data model. Columns 3-6 show similar results across the four metro areas. The estimated coefficient of residential density was larger than that of job density at commuting destination in Los Angeles and San Diego, while the opposite was the case in San Francisco and Sacramento.

Tables 8 and 9 present estimation results with residence and workplace neighborhood type dummy variables, respectively. The workplace dummy equations improved the fit (in terms of deviance, AIC, and BIC) compared with the residence dummies, except for the Los Angeles model. After controlling for poverty level, minority percentage, and commuting time, most neighborhood type dummy variables were significant with consistent signs across the four metro areas. Compared to an inner-ring suburban neighborhood type (reference Rtype 6), high-density inner city neighborhoods (Rtype 1-Rtype 3) had 100 to 160 percent more transit commuters in the four-MSA model. Rail transit neighborhoods in major downtown areas (Rtype 4) also showed transit ridership as high as in the densest neighborhoods. However, transit neighborhoods along rail transit lines outside major downtown areas (Rtype 7) showed moderate impacts. Coefficients in Rtype 7 areas were similar to or smaller than those in typical inner city neighborhoods (Rtype 5) in all metropolitan areas except Sacramento, where Rtype 7 had substantially higher transit ridership than other neighborhoods with comparable densities.

Estimated coefficients in workplace dummy regressions (Table 9) also show similar patterns across all four metropolitan areas. Consistent with the descriptive analysis, a higher concentration of transit commuting was observed than in Table 8 with residence neighborhood dummy variables. Commuting to regional primary and secondary centers showed 100 to 260 percent higher transit ridership than the reference workplace neighborhood type (Wtype 8) in the pooled 
Table 5: Percentage rate and share of transit commuters by workplace neighborhood type.

\begin{tabular}{|c|c|c|c|c|c|c|c|c|c|c|c|}
\hline \multicolumn{2}{|c|}{ Workplace neighborhoods } & \multicolumn{2}{|c|}{4 MSAs } & \multicolumn{2}{|c|}{ Los Angeles } & \multicolumn{2}{|c|}{ San Francisco } & \multicolumn{2}{|c|}{ San Diego } & \multicolumn{2}{|c|}{ Sacramento } \\
\hline & & Rate & Share & Rate & Share & Rate & Share & Rate & Share & Rate & Share \\
\hline Regio & Wtyl & 56.9 & 13 & NA & 0 & 56.9 & 30 & $\mathrm{NA}$ & 0 & NA & 0 \\
\hline Centers & Wtyp & 26.6 & 16 & 18.3 & 9.7 & 36.4 & 23.4 & 14.6 & 9.8 & 16 & 23.4 \\
\hline $\begin{array}{l}\text { Secondar } \\
\text { Centers }\end{array}$ & Wtype & 8.9 & 10.6 & 6.8 & 12.4 & 16.7 & 8.5 & 7.8 & 8.9 & 7.9 & 17.4 \\
\hline Edge & Wtyp & 3 & 5. & 3 & 6.3 & 3.3 & 4.7 & 2.9 & 9.7 & 1.2 & 3.8 \\
\hline \multirow{3}{*}{$\begin{array}{l}\text { Medium } \\
\text { Job Density }\end{array}$} & Wtyp & 6.8 & 10. & 7.9 & 14.5 & 93 & 6.1 & 3.1 & 12.8 & 2 & 9.9 \\
\hline & & 3.4 & 1 . & 0 & 1.4 & & & 3.9 & 5 & 2.8 & 6.7 \\
\hline & Wtype & 5.5 & 6. & 4.7 & 6.3 & 8. & 6.5 & 3.1 & 9.8 & 3.8 & 12.5 \\
\hline Industrial & Wtyp & 4.1 & 18.7 & 4.5 & 29.3 & 38 & 9.9 & 2.9 & 12.7 & 1.2 & 9.7 \\
\hline \multirow{3}{*}{$\begin{array}{l}\text { Mixed } \\
\text { Residential }\end{array}$} & Wtyp & 4.4 & 7 & 4.8 & 9.7 & 4.6 & 3.4 & 4.2 & 14.6 & 1.9 & 7.8 \\
\hline & Wtyp & 2.2 & 3. & 1.9 & 4 & 2.8 & 2.3 & 2.8 & 8.1 & 0.9 & 1.8 \\
\hline & Wtype11 & 3.1 & 3.2 & 3.8 & 3.8 & 3.1 & 2.4 & 1.8 & 5.0 & 1.0 & 2.8 \\
\hline \multirow{3}{*}{ Exurban } & & 1. & 1 & 1 & 1 & 1 & 0 & 2.1 & 2.9 & 0.7 & 1.9 \\
\hline & & 1. & 0. & 1. & 0.8 & 0.8 & 0 & NA & 0 & 2.7 & 2.1 \\
\hline & Wtype14 & 1.2 & 0 & 1.2 & 0 & NA & 0 & NA & 0 & NA & 0 \\
\hline \multicolumn{2}{|c|}{ Average/Total } & 5.7 & 100 & 4.6 & 100 & 9.2 & 100 & 3.5 & 100 & 2.6 & 100 \\
\hline
\end{tabular}

Note: Public transit includes five commuting modes: bus or trolley bus; streetcar or trolley car; subway or elevated rail; surface railroad; and ferryboat. Transit users' share of total commuters for each metropolitan area in Table 5 may be different from that of Table 4 because some commuters' trips originated from and terminated at places outside the metropolitan area.

data model. However, there was a noticeable difference in this tendency between Southern and Northern California metropolitan areas; the estimated coefficients of Wtypes 1-3 were larger in San Francisco and Sacramento than in Los Angeles and San Diego. Turning to edge-city-type suburban employment centers (Wtype 4), despite their relatively high employment density, transit ridership was not significantly high in all but the San Diego model. This result indicates that there are other factors affecting transit ridership beyond density (Krizek 2003a,b).

Regression models presented in Table 10 include all residence and workplace neighborhood types. Estimates with both neighborhood type dummy variables resulted in a better statistical fit than the estimations with only density variables. Addition of neighborhood type dummies adds complexity and improves explanatory power compared with the much simpler and more widely used density specifications.

Compared to the results in Tables 8 and 9, the size of estimated coefficients of both residence and workplace neighborhood types is smaller in Table 10 because both commuting origins and destinations are controlled. The reduction in the coefficient size of the top transit-commuting neighborhoods was more prominent for residence than workplace dummy variables. This corroborates the finding that neighborhood attributes in commuting destinations matter more than the physical characteristics in commuting origins.

\section{Discussion}

This paper presented two major findings. First, statistical cluster analysis can be used to successfully identify spatial clusters of residence and workplace neighborhoods with similar physical attributes such as density, street design, and transportation access (building on Krizek 2003a,b). Second, identified neighborhood types had significant impacts on transit commuting, especially in inner cities and major employment centers. However, rail transit neighborhoods outside central locations had only moderate effects and edge-city-type employment centers had little impact. We also found that workplace 


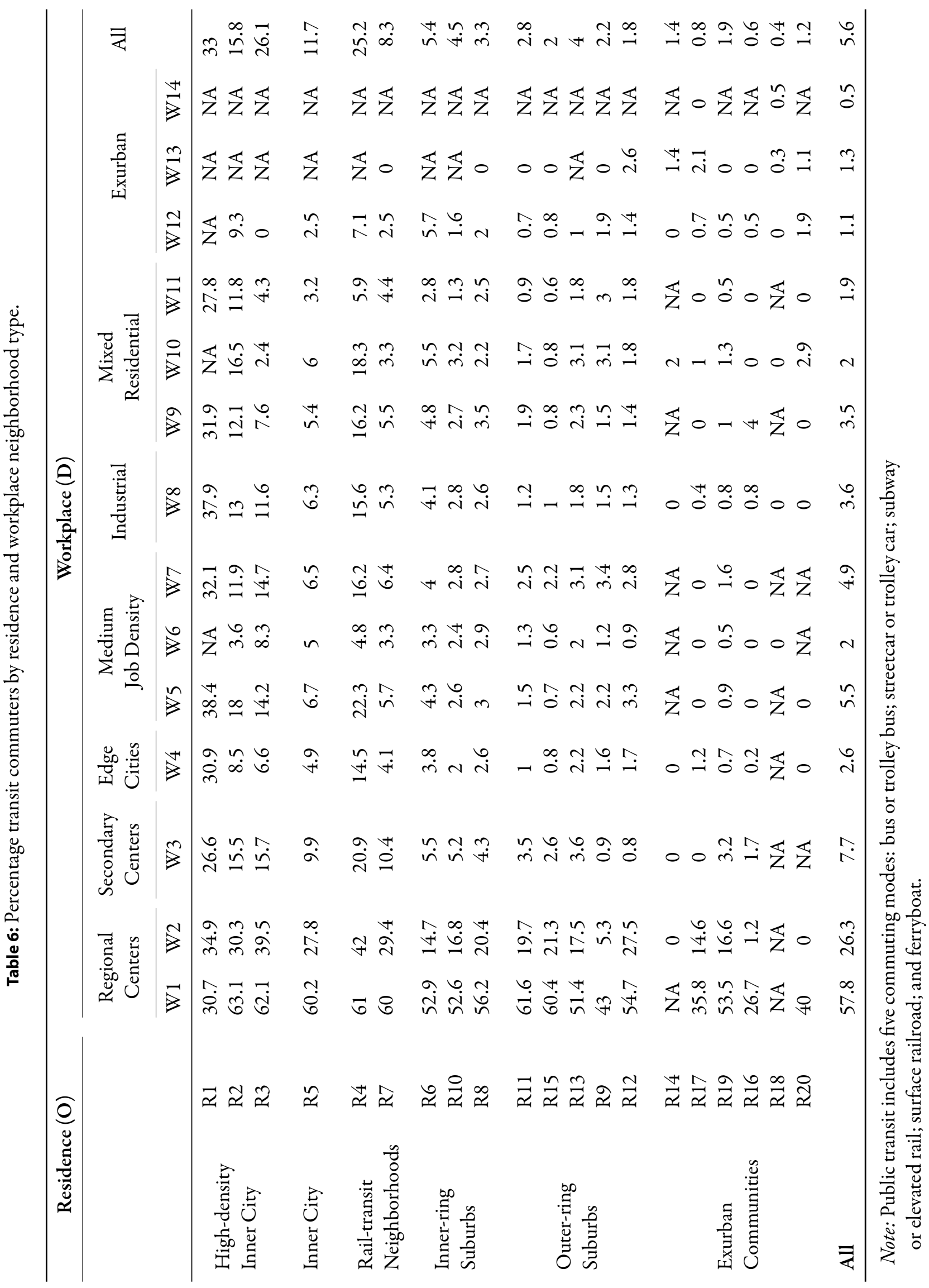


Table 7: Estimation results residence and workplace densities.

\begin{tabular}{|c|c|c|c|c|c|c|}
\hline & $4 \mathrm{MSAs}$ & $\begin{array}{c}4 \text { MSAs } \\
\text { (incl. origin } \\
\text { \& dest. densities) }\end{array}$ & Los Angeles & San Francisco & San Diego & Sacramento \\
\hline \multirow[t]{2}{*}{$\log \#$ commuters } & $1.086^{* * *}$ & $0.986^{* * *}$ & $0.995^{* * *}$ & $0.972^{* * *}$ & $0.918^{* * *}$ & $1.043^{* * *}$ \\
\hline & 11.4 & 72.5 & 47 & 47 & 25.4 & 19 \\
\hline \multirow[t]{2}{*}{ percent poverty } & $0.022^{* * *}$ & $0.0215^{* * *}$ & $0.0189^{* * *}$ & $0.0215^{* * *}$ & $0.019^{* * *}$ & $0.03^{* * *}$ \\
\hline & 73 & 14.2 & 27.3 & 17.7 & 10.9 & 10.9 \\
\hline \multirow[t]{2}{*}{ percent minority } & $0.0143^{* * *}$ & $0.0105^{* * *}$ & $0.0148^{* * *}$ & $0.00515^{* * *}$ & $0.0111^{* * *}$ & $0.00311^{* *}$ \\
\hline & 3.11 & 3.14 & 33.8 & 13.3 & 12.8 & 2.11 \\
\hline \multirow[t]{2}{*}{ log driving time } & $1.086^{* * *}$ & $0.775^{* * *}$ & $0.775^{* * *}$ & $0.765^{* * *}$ & $0.697^{* * *}$ & $0.598^{* * *}$ \\
\hline & 6.83 & 40.8 & 30.3 & 26.2 & 13 & 7.44 \\
\hline \multirow[t]{2}{*}{ D San Francisco } & $1^{* * *}$ & $0.731^{* * *}$ & & & & \\
\hline & 6.39 & 5.34 & & & & \\
\hline \multirow[t]{2}{*}{ D San Diego } & 0.107 & $0.258^{* * *}$ & & & & \\
\hline & 1.02 & 3.97 & & & & \\
\hline \multirow[t]{2}{*}{ D Sacramento } & 0.204 & $0.439^{* * *}$ & & & & \\
\hline & 1.27 & 3.17 & & & & \\
\hline log pop density & & $0.363^{* * *}$ & $0.468^{* * *}$ & $0.326^{* * *}$ & $0.422^{* * *}$ & $0.159^{* * *}$ \\
\hline Residence & & 8.36 & 23.6 & 21.2 & 12.7 & 4.34 \\
\hline log job density & & $0.358^{* * *}$ & $0.186^{* * *}$ & $0.467^{* * *}$ & $0.29^{* * *}$ & $0.449^{* * *}$ \\
\hline Workplace & & 3.96 & 15.6 & 48.7 & 12.5 & 17.4 \\
\hline \multirow[t]{2}{*}{ Constant } & $-8.146^{* * *}$ & $-8.381^{* * *}$ & $-8.539^{* * *}$ & $-7.547^{* * *}$ & $-7.6^{* * *}$ & $-7.275^{* * *}$ \\
\hline & -14.3 & -48 & -63.2 & -58.6 & -29.2 & -19 \\
\hline Observations & 130075 & 130074 & 67566 & 38950 & 14192 & 9366 \\
\hline Deviance & 296744 & 254442 & 126626 & 79204 & 27103 & 16204 \\
\hline Aic & 3.475 & 3.149 & 2.814 & 3.856 & 2.851 & 2.519 \\
\hline $\mathrm{Bic}$ & -1234908 & -1277174 & -624688 & -332425 & -108512 & -69382 \\
\hline Log likelihood & -225967 & -204816 & -95061 & -75092 & -20222 & -11789 \\
\hline
\end{tabular}

The dependent variable of all models is log number of transit commuters.

$Z$-stat based on robust standard errors is below each coefficient.

${ }^{* * *} p<0.01,{ }^{* *} p<0.05,{ }^{*} p<0.1$.

attributes matter more than residential neighborhood types, especially in San Francisco and Sacramento.

Although the primary purpose of this paper was to enhance our understanding of the links between neighborhood attributes and transit commuting, the approach taken in this research can also be used to improve travel demand forecasting practices. Most four-step travel demand forecasting models (especially trip generation and mode choice modules) do not use neighborhood attribute variables as travel predictors, and hence cannot capture the travel impacts of various neighborhood-level land-use strategies. Cervero (2006) suggested some alternative approaches such as direct or off-line modeling as a fix. Estimation and use of different parameters for various neighborhood types in travel demand modeling can also be an addition to the tool box.
Many planners and public policy makers have avoided the central issues associated with transit's long-term decline by arguing that long-term changes in the built environment and metropolitan settlement patterns can stimulate a major turnaround in transit ridership, particularly for commuting. This perspective focuses on dealing with transportation issues via urban form solutions rather than on the question of how our transportation systems can best be adapted to contemporary urban forms. These efforts often overlooked alternative solutions: pricing to control negative externalities (congestion and emissions); deregulation and privatization, e.g. by promoting paratransit (Roth 2006); and the effects of market forces (e.g. the recent uptick in transit use associated with higher gasoline prices). 

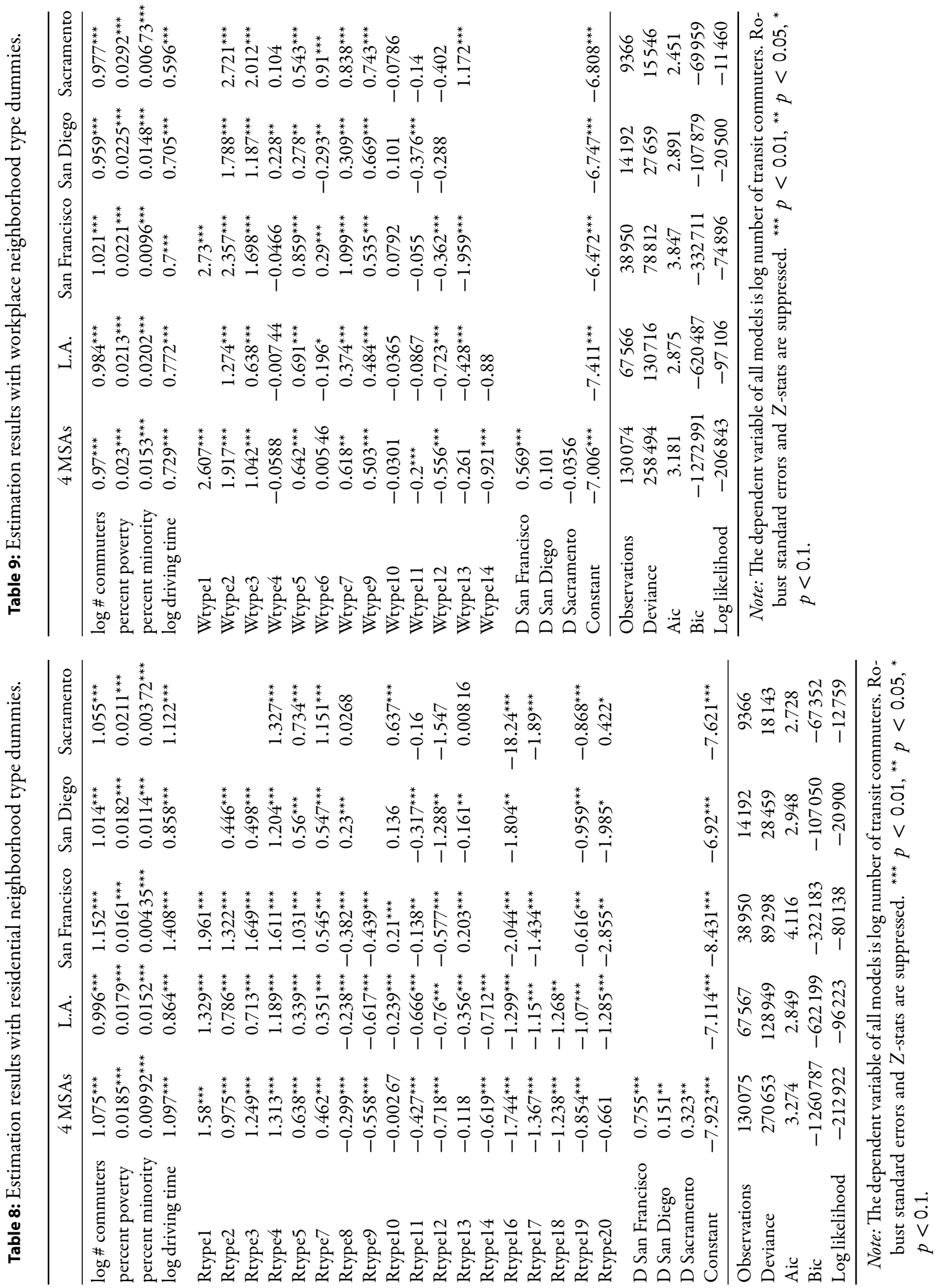
Table 10: Estimation results with both residential and workplace neighborhood type dummies.

\begin{tabular}{|c|c|c|c|c|c|}
\hline & $4 \mathrm{MSAs}$ & Los Angeles & San Francisco & San Diego & Sacramento \\
\hline $\log \#$ commuters & $0.978^{* * *}$ & $1.003^{* * *}$ & $1.012^{* * *}$ & $0.979^{* * *}$ & $1.03^{* * *}$ \\
\hline percent poverty & $0.0197^{* * *}$ & $0.0181^{* * *}$ & $0.0191^{* * *}$ & $0.0194^{* * *}$ & $0.0262^{* * *}$ \\
\hline percent minority & $0.0122^{* * *}$ & $0.0162^{* * *}$ & $0.0076^{* * *}$ & $0.0121^{* * *}$ & $0.00589^{* * *}$ \\
\hline log driving time & $0.785^{* * *}$ & $0.791^{* * *}$ & $0.817^{* * *}$ & $0.79^{* * *}$ & $0.777^{* * *}$ \\
\hline Rtype1 & $1.2^{* * *}$ & $1.126^{* * *}$ & $1.229^{* * *}$ & & \\
\hline Rtype2 & $0.889^{* * *}$ & $0.746^{* * *}$ & $1.069^{* * *}$ & $0.426^{* *}$ & \\
\hline Rtype3 & $0.939^{* * *}$ & $0.652^{* * *}$ & $1.103^{* * *}$ & $0.443^{* *}$ & \\
\hline Rtype 4 & $1.098^{* * *}$ & $1.065^{* * *}$ & $1.238^{* * *}$ & $1.137^{* * *}$ & $1.182^{* * *}$ \\
\hline Rtype 5 & $0.463^{* * *}$ & $0.292^{* * *}$ & $0.687^{* * *}$ & $0.516^{* * *}$ & $0.391^{*}$ \\
\hline Rtype7 & $0.466^{* * *}$ & $0.32^{* * *}$ & $0.627^{* * *}$ & $0.522^{* * *}$ & $0.922^{* * *}$ \\
\hline Rtype8 & -0.0972 & $-0.156^{* * *}$ & -0.00342 & $0.28^{* * *}$ & 0.15 \\
\hline Rtype9 & -0.178 & $-0.564^{* * *}$ & $0.163^{*}$ & & \\
\hline Rtype10 & -0.0693 & $-0.249^{* * *}$ & 0.104 & 0.0552 & $0.534^{* * *}$ \\
\hline Rtype11 & $-0.421^{* * *}$ & $-0.628^{* * *}$ & $-0.19^{* * *}$ & $-0.225^{* *}$ & $-0.236^{* *}$ \\
\hline Rtype12 & $-0.383^{*}$ & $-0.687^{* * *}$ & -0.0242 & $-0.959^{* *}$ & -0.92 \\
\hline Rtype13 & -0.15 & $-0.352^{* * *}$ & $0.152^{* * *}$ & -0.132 & 0.125 \\
\hline Rtype14 & $-0.853^{* * *}$ & $-0.84^{* * *}$ & & & \\
\hline Rtype16 & $-1.294^{* * *}$ & $-0.854^{* * *}$ & $-1.335^{* * *}$ & $-1.717^{* *}$ & $-16.84^{* * *}$ \\
\hline Rtype17 & $-0.875^{* * *}$ & $-0.878^{* * *}$ & $-0.731^{* * *}$ & & $-1.083^{* *}$ \\
\hline Rtype18 & $-1.607^{* * *}$ & -1.521 & & & \\
\hline Rtype19 & $-0.768^{* * *}$ & $-1.06^{* * *}$ & $-0.47^{* * *}$ & $-0.924^{* * *}$ & $-0.58^{* * *}$ \\
\hline Rtype20 & -0.575 & $-1.21^{* * *}$ & $-2.369^{* * *}$ & -1.745 & $1.071^{* *}$ \\
\hline Wtype1 & $2.494^{* * *}$ & & $2.572^{* * *}$ & & \\
\hline Wtype2 & $1.707^{* * *}$ & $1.13^{* * *}$ & $2.053^{* * *}$ & $1.772^{* * *}$ & $2.7^{* * *}$ \\
\hline Wtype3 & $0.804^{* *}$ & $0.373^{* * *}$ & $1.379^{* * *}$ & $1.148^{* * *}$ & $1.955^{* * *}$ \\
\hline Wtype4 & -0.0285 & 0.0243 & 0.00698 & $0.201^{* *}$ & 0.0847 \\
\hline Wtype 5 & $0.461^{* * *}$ & $0.471^{* * *}$ & $0.624^{* * *}$ & $0.245^{* *}$ & $0.601^{* * *}$ \\
\hline Wtype6 & 0.0779 & -0.0318 & $0.403^{* * *}$ & $-0.277^{* *}$ & $0.921^{* * *}$ \\
\hline Wtype7 & $0.49^{* *}$ & $0.284^{* * *}$ & $0.855^{* * *}$ & $0.328^{* * *}$ & $0.94^{* * *}$ \\
\hline Wtype9 & $0.586^{* * *}$ & $0.539^{* * *}$ & $0.668^{* * *}$ & $0.716^{* * *}$ & $0.898^{* * *}$ \\
\hline Wtype10 & $0.326^{* * *}$ & $0.43^{* * *}$ & $0.433^{* * *}$ & $0.31^{* * *}$ & 0.315 \\
\hline Wtype11 & -0.0825 & -0.039 & 0.0904 & $-0.235^{*}$ & -0.0969 \\
\hline Wtype12 & -0.0442 & $-0.24^{* * *}$ & 0.111 & 0.00226 & -0.00941 \\
\hline Wtype13 & $0.589^{* * *}$ & 0.387 & -0.839 & & 0.274 \\
\hline Wtype14 & $0.746^{* * *}$ & 0.513 & & & \\
\hline Dsf & $0.454^{* * *}$ & & & & \\
\hline Dsd & $0.17^{* * *}$ & & & & \\
\hline Dsa & 0.171 & & & & \\
\hline Constant & $-7.096^{* * *}$ & $-7.238^{* * *}$ & $-7.013^{* * *}$ & $-7.017^{* * *}$ & $-7.598^{* * *}$ \\
\hline Observations & 130074 & 67566 & 38950 & 14192 & 9366 \\
\hline Deviance & 246642 & 125565 & 74185 & 26651 & 14841 \\
\hline Aic & 3.09 & 2.799 & 3.729 & 2.822 & 2.378 \\
\hline $\mathrm{Bic}$ & -1284632 & -625438 & -337169 & -108763 & -70553 \\
\hline $\mathrm{Ll}$ & -200917 & -94530 & -72582 & -19996 & -11108 \\
\hline
\end{tabular}

Note: The dependent variable of all models is log number of transit commuters. Robust standard errors and $Z$-stats are suppressed. ${ }^{* * *} p<0.01,{ }^{* *} p<0.05,{ }^{*} p<0.1$. 
Redesigning neighborhoods to encourage transit use would take a long time and requires further empirical support. Our research exploits available data to identify the neighborhood types in the metropolitan areas of California to determine if they make a statistical difference to transit commuting. Examining the data via cluster analysis and tests of the relationship between commuting mode choice and predictor variables suggests some useful directions for further research. We found that, ceteris paribus, some neighborhood types matter, either positively or negatively, especially at commuting destinations. Rail transit access in residential neighborhoods outside central locations had only moderate effects on transit commuting.

\section{References}

Bagley, M. and P. Mokhtarian. 2002. The impact of residential neighborhood type on travel behavior: A structural equations modeling approach. The Annals of Regional Science, 36(2):279-297. doi: 10.1007/s001680200083.

Bagley, M., P. Mokhtarian, and R. Kitamura. 2002. A methodology for the disaggregate, multidimensional measurement of residential neighbourhood type. Urban Studies, 39(4):689-704. doi: 10.1080/00420980220119525.

Barnes, G. 2005. The importance of trip destination in determining transit share. Journal of Public Transportation, $8(2): 1-15$.

Boarnet, M. and R. Crane. 2001a. The influence of land use on travel behavior: Specification and estimation strategies. Transportation Research Part A: Policy and Practice, 35(9):823-845. doi: 10.1016/S0965-8564(00)00019-7.

Boarnet, M. and R. Crane. 2001b. Travel by Design: The Influence of Urban Form on Travel. New York: Oxford University Press.

Cao, X., P. Mokhtarian, and S. Handy. 2008. Examining the impacts of residential self-selection on travel behavior: Methodologies and empirical findings. Research Report UCD-ITS-RR-08-25, Institute of Transportation Studies, University of California, Davis. URL http://pubs. its.ucdavis.edu/publication_detail.php?id=1194.

Cervero, R. 2002. Built environments and mode choice: Next term toward a normative framework. Transportation Research Part D: Transport and Environment, 7(4):265-284. doi: 10.1016/S1361-9209(01)00024-4.

Cervero, R. 2006. Alternative approaches to modeling the travel-demand impacts of smart growth. Journal of the American Planning Association, 72(3):285-295. doi: 10.1080/01944360608976751.
Cervero, R. 2007. Transit-oriented development's ridership bonus: A product of self-selection and public policies. Environment and Planning A, 39(9):2068-2085. doi: $10.1068 / \mathrm{a} 38377$.

Cervero, R. and R. Gorham. 1995. Commuting in transit versus automobile neighborhoods. Journal of the American Planning Association, 61(2):210-225. doi: 10.1080/01944369508975634.

Cervero, R. and K. Kockelman. 1997. Travel demand and the 3Ds: Density, diversity, and design. Transportation Research Part D: Transport and Environment, 2(3):199-219. doi: 10.1016/S1361-9209(97)00009-6.

Chatman, D. 2003. How density and mixed uses at the workplace affect personal commercial travel and commute mode choice. Travel Demand and Land Use 2003, 1831:193-201. doi: 10.3141/1831-22.

Crane, R. 2000. The influence of urban form on travel: An interpretive review. Journal of Planning Literature, 15(1):3-23. doi: 10.1177/08854120022092890.

Crane, R. and R. Crepeau. 1998. Does neighborhood design influence travel? a behavioral analysis of travel diary and GIS data. Transportation Research Part D: Transport and Environment, 3(4):225-238. doi: 10.1016/S13619209(98)00001-7.

Dueker, K. and M. Bianco. 1999. Light-rail-transit impacts in Portland: The first ten years. Transportation Research Record, 1685:171-180. doi: 10.3141/1685-22.

Dunphy, R. and D. Porter. 2006. Manifestations of development goals in transit-oriented projects. Transportation Research Record, 1977:172-178. doi: 10.3141/1977-22.

Ewing, R. and R. Cervero. 2001. Travel and the built environment: A synthesis. Transportation Research Record, 1780:87-114. doi: 10.3141/1780-10.

Frank, L., M. Bradley, S. Kavage, J. Chapman, and T. K. Lawton. 2008. Urban form, travel time, and cost relationships with tour complexity and mode choice. Transportation, 35(1):37-54. doi: 10.1007/s11116-007-9136-6.

Frank, L. and G. Pivo. 1994. Impacts of mixed use and density on utiliztion of three modes of travel: Single-occupant vehicle, transit, and walking. Transportation Research Record, 1466:44-52.

Gordon, P., B. Lee, J. E. Moore, and H. Richardson. 2006. Non-work trips revisited: A neglected issue in urban transportation.

Gordon, P. and H. Richardson. 1989. Counting non-work trips: The missing link in transportation, land use and urban policy. Urban Land, 48(9):6-12. 
Handy, S. 1996. Understanding the link between urban form and nonwork travel behavior. Journal of Planning Education and Research, 15(3):183-198. doi: 10.1177/0739456X9601500303.

Handy, S. 2005. Smart growth and the transportation-land use connection: What does the research tell us? International Regional Science Review, 28(2):146-167. doi: 10.1177/0160017604273626.

Kitamura, R., P. Mokhtarian, and L. Laidet. 1997. A microanalysis of land use and travel in five neighborhoods in the San Francisco Bay area. Transportation, 24(2):125-158. doi: 10.1023/A:1017959825565.

Krizek, K. 2003a. Operationalizing neighborhood accessibility for land use-travel behavior research and regional modeling. Journal of Planning Education and Research, 22(3):270-287. doi: 10.1177/0739456X02250315.

Krizek, K. 2003b. Residential relocation and changes in urban travel: Does neighborhood-scale urban form matter? Journal of the American Planning Association, 69(3):265-281. doi: 10.1080/01944360308978019.

Messenger, T. and R. Ewing. 1996. Transit-oriented development in the Sun Belt. Transportation Research Record, 1552:145-153. doi: 10.3141/1552-20.

Murphy, A. 2010. A dynamic model of housing supply. Working Paper, URL http://apps.olin.wustl.edu/faculty/ murphya/.

Roth, G., ed. 2006. Street Smart: Competition, Entrepreneurship, and the Future of Roads. Brunswick, NJ: Transaction Publishers.

Schwanen, T. and P. Mokhtarian. 2005. What affects commute mode choice: Neighborhood physical structure or preferences toward neighborhoods? Journal of Transport Geography, 13(1):83-99. doi: 10.1016/j.jtrangeo.2004.11.001.

Smith, J. and M. Saito. 2001. Creating land-use scenarios by cluster analysis for regional land-use and transportation sketch planning. Journal of Transportation and Statistics, 4(1):39-49. URL http://www.bts.gov/publications/ journal_of_transportation_and_statistics/volume_04_ number_01/paper_03/index.html.

Southworth, M. 1997. Walkable suburbs?: An evaluation of neotraditional communities at the urban edge. Journal of the American Planning Association, 63(1):28-44. doi: 10.1080/01944369708975722.

Srinivasan, S. 2002. Quantifying spatial characteristics of cities. Urban Studies, 39(11):2005-2028. doi: 10.1080/0042098022000011335.
U.S. Census Bureau. 1999. Metropolitan areas and components defined by Office of Management and Budget.

U.S. Census Bureau. 2002a. Census 2000 summary file 3.

U.S. Census Bureau. 2002b. TIGER/Line files.

U.S. Census Bureau. 2003. Census 2000, special tabulation: Census transportation planning projects.

Vance, C. and R. Hedel. 2007. The impact of urban form on automobile travel: Disentangling causation from correlation. Transportation, 34(5):575-588. doi: 10.1007/s11116-007-9128-6.

Wendell Cox Consultancy. US urban personal vehicle \& public transport market share from 1900. URL http://www. publicpurpose.com/ut-usptshare 45.htm.

Wooldridge, J. 2002. Econometric Analysis of Cross Section and Panel Data. MIT Press. 